\title{
Passive Navigation Using Image Irradiance Tracking
}

\author{
P. K. A. Menon ${ }^{1}$
}

\section{Georgia Institute of Technology}

Rotorcraft operating at low altitudes require navigational schemes for detecting terrain and obstacles. Due to the nature of the missions to be accomplished and available power onboard, a passive navigation scheme is desirable in this situation. This paper describes the development of a passive navigation scheme using optical image sequences and vehicle motion variables from an onboard inertial navigation scheme. This approach combines the geometric properties of perspective projection and a feedback irradiance tracking scheme at each pixel in the image to determine the range to various objects within the field-of-view. Derivation of the numerical algorithm and simulation results are given. Due to the feedback nature of the implementation, the computational scheme is robust. Other applications of the proposed approach include navigation for autonomous planetary rovers and telerobots.

This research was supported under NASA grant NAG2-463.

\section{References}

1) Horn, B. K. P., Robot Vision, McGraw-Hill, New York, 1986.

2) Sridhar, B. and Phatak, A. V., "Simulation and Analysis of Image-Based Navigation System for Rotorcraft Low-Altitude Flight," AHS National Specialist's Meeting on Automation Applications of Rotorcraft, April 4-6, 1988, Atlanta, GA.

1Mailing address: MS 210-9, NASA Ames Research Center, Moffett Field, CA 94035. 